
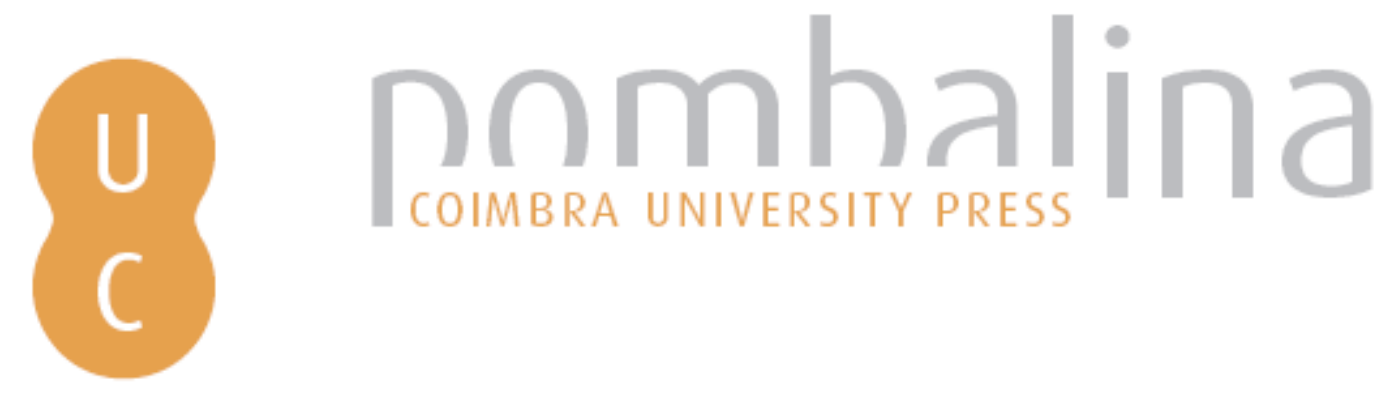

\title{
"No habrá transubstanciación ni víctima emisaria!": subversión del mito y desencanto en Antígona... ¡cerda! de Luis Riaza
}
Autor(es):
Rivas, Ezequiel Gustavo
Publicado por: Centro de Estudos Clássicos e Humanísticos da Universidade de Coimbra; Imprensa da Universidade de Coimbra
URL persistente:
URI:http://hdl.handle.net/10316.2/30283
DOI:
DOI:http://dx.doi.org/10.14195/978-989-721-038-9_53
Accessed : $\quad$ 26-Apr-2023 14:51:47

A navegação consulta e descarregamento dos títulos inseridos nas Bibliotecas Digitais UC Digitalis, UC Pombalina e UC Impactum, pressupõem a aceitação plena e sem reservas dos Termos e Condições de Uso destas Bibliotecas Digitais, disponíveis em https://digitalis.uc.pt/pt-pt/termos.

Conforme exposto nos referidos Termos e Condições de Uso, o descarregamento de títulos de acesso restrito requer uma licença válida de autorização devendo o utilizador aceder ao(s) documento(s) a partir de um endereço de IP da instituição detentora da supramencionada licença.

Ao utilizador é apenas permitido o descarregamento para uso pessoal, pelo que o emprego do(s) título(s) descarregado(s) para outro fim, designadamente comercial, carece de autorização do respetivo autor ou editor da obra.

Na medida em que todas as obras da UC Digitalis se encontram protegidas pelo Código do Direito de Autor e Direitos Conexos e demais legislação aplicável, toda a cópia, parcial ou total, deste documento, nos casos em que é legalmente admitida, deverá conter ou fazer-se acompanhar por este aviso.

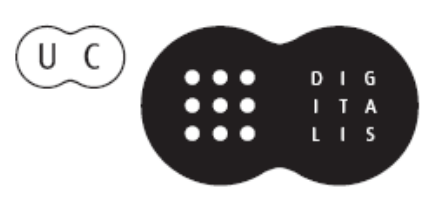




\section{De ayer a hoy}

\section{Influencias clásicas en la literatura}

\section{Aurora López, Andrés Pociña, Maria de Fátima Silva (coords.)}




\title{
“ ¿NO HABRÁ TRANSUBSTANCIACIÓN NI VÍCTIMA EMISARIA!”: SUBVERSIÓN DEL MITO Y DESENCANTO EN ANTÍGONA... ;CERDA! De Luis Riaza
}

Ezequiel Gustavo Rivas Universidad de Buenos Aires

\begin{abstract}
Antígona de Sófocles, considerada durante siglos la mejor tragedia de la producción clásica, ha sido leída e interpretada por diversos ejes, tales como el filosófico, el religioso y el político. Este último, donde la dupla Antígona-Creonte funcionaría como encarnación de los ideales de liberación y revolución frente al poder del establishment dominante. En la España de la última etapa de la dictadura franquista y los primeros años de democracia, el mito de Antígona es re-interpretado y re-leído desde otra óptica: el desencanto ante la corrupción y la inutilidad del sacrificio por los ideales. Así, Riaza, mediante diversos procedimientos tomados del teatro de vanguardia subvierte el mito de la heroína, reinterpretándolo y haciéndolo productivo a la luz de la historia reciente.
\end{abstract}

La figura de Antígona como representante de los valores de libertad y convicción de las propias ideas se inscribe en la larga tradición literaria del texto de Sófocles. Antígona, considerada durante siglos la mejor tragedia de la producción clásica, ha sido leída e interpretada a partir de diversos ejes, entre ellos el filosófico, donde la obra representaría, según Nussbaum ${ }^{1}$, un estadio primitivo de la vida y del pensamiento ético; el eje religioso, con la célebre diatriba entre la "leyes no escritas" sostenidas por Antígona y las "leyes de la ciudad" fijadas por Creonte. Pero sobre todo el eje político, donde la dupla Antígona-Creonte funcionaría como encarnación de los ideales de liberación y revolución frente al poder del establishment dominante, ha sido uno de los ejes más productivos en cuanto a interpretación de esta tragedia. El mito del personaje de la hija de Edipo que se enfrenta incluso hasta la muerte por defender sus convicciones es un Leitmotiv, por ejemplo, del movimiento de independencia griego a fines del siglo XIX. En el siglo XX, las versiones de Anouihl y Brecht son cabales ejemplos de esta última lectura política.

Por otra parte, en España, en el contexto del final de la dictadura franquista y su transición a la democracia, asistimos no sólo a un cambio en la escena política sino además a una importante transformación en los paradigmas teatrales. Las vanguardias, que hasta el momento habían influido en la escena de modo decisivo durante la dictadura de Franco como un modo de

\footnotetext{
${ }^{1}$ Nussbaum (1995: 90).
} 
contestación al régimen y como un lugar de experimentación y libertad, llegan en la nueva democracia a una especie de anquilosamiento y aburguesamiento en el marco de una "institucionalización" de la escena española. La escritura teatral ya no tiene el valor de combate contra el dictador, pues éste ha muerto. En este período, signado por el modelo cultural del PSOE (que ganara las elecciones de 1982), el teatro de resistencia se ve en la obligación de saltar casi de modo directo de la clandestinidad en la que operaba a los escenarios institucionales ${ }^{2}$. Además, este teatro convive con las producciones puramente comerciales, carentes de valor estético y sin ninguna aportación para la actividad teatral revitalizada. Hay, asimismo, una apuesta de parte de los aparatos del Estado en cuanto a la política cultural a una "normalización" que se tradujo, en cierta forma, en modelos estilísticos claros marcados por un tono realista, factura clásica y un volver a mirar los modelos del siglo XIX. Finalmente, el auge del cine como lenguaje y su conquista del espacio del ocio sancionan la postergación de un teatro que, en vez de reafirmar sus postulados como defensa, intenta competir con los nuevos lenguajes que le son rivales. Todo esto provoca un desplazamiento del teatro hacia la masificación y el distorsionamiento de su dimensión social ${ }^{3}$. La escritura de Riaza se ubica así en esta encrucijada histórica y funciona como un verdadero síntoma del cambio de paradigmas. Su dramaturgia, que se nutre a su vez de autores como Artaud y Beckett, pero también Weiss, Ionesco, Brook y de la tradición vanguardista presente en España desde principios del siglo XX (Valle-Inclán, García Lorca), muestra diversos elementos permanentes, que funcionan como instrumentos y constituyentes de su propia poética, como son la irrupción en la escena de objetos inanimados, máscaras, muñecos y sustitutos de humanos y animales; el uso del espacio teatral como símbolo despojado pero a su vez orientado hacia la ceremonia; el uso del mito clásico y la preponderancia de la temática del poder.

Nuestra propuesta de lectura abordará el análisis de Antígona ... ; Cerda! a partir de dos ejes que atraviesan la primera producción riaciana, signada por la transición histórica: el del desencanto ante la corrupción que proviene del poder y el de la inutilidad del sacrificio por los ideales. El mito de Antígona es en esta obra re-interpretado y re-leído por estos dos sentimientos que se respiraban en el aire de la España de fines de los setenta y comienzo de los ochenta, sentimientos ligados, en última instancia, a la temática del poder. Por otro lado, y conformando un principio esencial del "mundo riaciano", el lente del sarcasmo permite "contemplar el tinglado de la sociedad a quienes lo niegan

\footnotetext{
${ }^{2}$ Cf. Ruiz Pérez (2006: 19).

${ }^{3}$ Cf. Ruiz Pérez (2006: 20).
} 
desde adentro al tiempo que se instalan en él", subvirtiendo el mito clásico y reinterpretándolo.

No es la primera vez que en el ámbito de la dramaturgia española contemporánea el mito de Antígona sirve de metáfora para "explicar" la situación presente de opresión, censura y falta de libertad. Es frecuente en la producción del período franquista ver a esta heroína como figura del deseo de reconciliación y perdón en respuesta a la lucha fratricida producto de la Guerra Civil, pero al mismo tiempo como un símbolo de resistencia contra la dictadura de Franco 5 . En el particular mundo riaciano, Antígona es a la vez metáfora y símbolo de una realidad doble, realidad que se nutre del pasado fratricida y devastador de la Guerra Civil pero también del presente impregnado de una atmósfera de desencanto respecto de los ideales revolucionarios y contestatarios al régimen que, frente a la democracia lograda y la institucionalización cultural, en especial en lo concerniente al teatro, ya no tenían sentido. El desencanto viene así a sustituir esa voluntad de lucha contra la dictadura, y en última instancia contra el poder totalitario, que marcó a toda una generación.

\section{El mito de Antígona y el conflicto trágico}

En la obra de Sófocles es sin lugar a dudas donde hallamos la fuente primaria para el mito de Antígona ${ }^{6}$. Como sabemos, la pelea fratricida entre los hijos de Edipo, Etéocles y Polinices por el reino de Tebas pone en escena a nuestro personaje que intenta rendir los debidos honores fúnebres a su hermano, condenado a no ser enterrado por Creonte. La transgresión a esta orden desencadena la máquina trágica poniendo en evidencia el conflicto: la desobediencia de las leyes de la ciudad emanadas del tirano se oponen a las leyes no escritas. La actitud de Antígona plantea una subversión de los valores cívicos con implicancias éticas y políticas para Creonte, puesto que por una parte el muerto pertenecía a la familia cercana y dejarlo insepulto habría sido un franco quebrantamiento de la tradición ético-religiosa, pero por otra parte, como se había convertido en enemigo y "traidor", Polinices debía ser abandonado insepulto y sin honras fuera de los límites de la ciudad ${ }^{7}$. Creonte neutraliza esta tensión evidente para el auditorio, utilizando el vocabulario ético tradicional para hablar sobre el bienestar de la ciudad, pero al mismo tiempo transformándolo y alejándose de su uso ordinario y de la tradición. Para el tirano, lo bueno (agathón) y lo malo (kakón) se identifican con lo bueno y lo malo para el bienestar de la

\footnotetext{
${ }^{4}$ Miras, prólogo-introducción a Antígona... ¡ Cerda! (2006: 248).

5 Así Espriu, Antígona (1939); Jiménez Romero, Oratorio: Antígona (1969); Bergamín, Antígona y la sangre (1983). Cf. Ragué-Arias (2005: 14).

${ }^{6}$ Sobre el mito de Antígona y sus fuentes, cf. Grimal (1981: 33).

${ }^{7}$ Cf. Nussbaum (1995: 95).
} 
ciudad $^{8}$. De ahí que Antígona sea, en cuanto a su comportamiento, la peor ( $k a k e ̂)$, puesto que su ejemplo es de una maldad, a los ojos de su tío, civil: "Éste es mi pensamiento, y que nunca los malvados obtendrán más honras de mi que los justos; pero todo benefactor de esta ciudad, una vez muerto o viviendo será honrado por mi". Creonte se ubica en el centro del conflicto trágico, trasformando sus decisiones autoritarias, que chocan con la tradición, y constituyéndolas como leyes que deben obedecerse. Esto le valdrá la peor de las catástrofes, al darse cuenta de su error y su ceguera. Antígona, quien firme en sus convicciones y resolución, decide continuar adelante con su cometido, enfrenta al tirano y se transforma en heroína, no como ejemplo para el auditorio ateniense (su actitud contumaz es justamente su error) pero lo será para la posteridad. Sófocles presenta la figura de la hija de Edipo como un medio para que resalte el héroe trágico, el tirano autoritario y obnubilado por el poder.

\section{La princesa Pantígona}

Ahora bien, Riaza cambiará los polos al servirse de la historia de Antígona. Ya no será Creonte el protagonista que lleve sobre sí el dilema trágico, sino esta muchacha que adquiere en cierta forma, caracteres de su par opuesto. Toda la pieza estará atravesada por la duplicidad. Desde el Prefacio poético Riaza presenta a Antígona como un personaje que es uno y doble a la vez, en este sentido, muy alejado de su modelo clásico. El título, ya sugerente, muestra la duplicidad del personaje que contrasta con la enterza que se aprecia en el que nos trasmite Sófocles:

"PREFACIO POÉTICO PARA PENETRAR ENTRE PRÓLOGO Y PIEZA, CON LA PERSONALIDAD PROMISCUA DE LA PRINCIPAL PROTAGONISTA, LA PLURAL PRINCESA PANTÍGONA.”

La aliteración buscada refuerza el doble: Antígona es "pantígona", "promiscua" y "plural". Es imagen del ideal revolucionario por excelencia, reforzado por la imaginería en torno al color rojo: "Encarnación de la revolución, / avanzas a través de tres mil años / con tu estandarte color sangre / alrededor de tu pujante pecho, / una túnica hecha girones / y el ombliguito al aire / e, incrustado en él, / el piercing primoroso / de un rojo y rabioso rubi"10. También en la didascalia de escenografía y vestuario, "Antígona" tiene "una túnica roja con a las vestiduras del teatro clásico griego"11.

\footnotetext{
${ }^{8}$ Nussbaum (1995: 96).

${ }^{9}$ Nussbaum (1995: 96).

${ }^{10}$ Riaza, Antígona... ¡ Cerda! (1983: 255, vv. 1-9).

${ }^{11}$ Riaza, Antígona... ; Cerda! (1983: 260).
} 
El primer quiebre en el texto donde Riaza plantea una doble faceta del personaje: "Petite putain respectueuse"12. Este verso, además de mantener la aliteración del título sobre el sonido de la labial sorda, funciona como un verdadero oxímoron y metáfora anticipatoria: Antígona es respetuosa de lo que los dioses dispusieron sobre el tratamiento fúnebre, y por ende, al nivel semántico general de la obra, respetuosa de modelo clásico, pero al mismo tiempo es una petite putain, una 'putita', sintagma que introduce la nueva caracterización de Antígona, en choque con la tradición clásica, y en clave del eje político, anticipando la actitud de muchos supuestos "contestatarios" que se "vendieron" por dinero al poder de turno. Ella es encarnación de la "furia siempre dispuesta / a rebelarse contra toda tiranía" a través de los siglos y en todos los niveles: mítico (Creonte), histórico (Pericles, Tiberio), religioso (obispo Cauchon, quien condenó a Juana de Arco) y político (mariscal Pétain, jefe de estado en la Francia ocupada por el Reich y colaboracionista). En último término, el "tetrarqueja de El Pardo" cierra la lista y es una clara alusión a Franco, quien habitara en el Palacio de E1 Pardo, una vez terminada la Guerra Civil.

Entre los versos 33 y 52 Riaza retoma el mito, haciéndonos saber que Antígona prefirió la muerte como reacción frente al tirano: "Todo por dar preferencia, / sobre el buche de los abantos, / a las tripas alargadas / de las larvas croque-morts, [...] terminando por ello / en un fúnebre agujero / con el bimen intacto / para ser desvirgadita / por Monsieur Death, / a no ser que fuera / por Mister Mort." Efectivamente, Antígona muere sin poder desposarse con Hemón, hijo de Creonte, al cual estaba prometida: "Es el Aqueronte con quien me voy a desposar"13. Riaza rompe la entereza de Antígona y evidenciando su doblez, diciendo que "más te hubiera valido / servirte de tu otra mitad / para ser deszoncellada". La otra mitad, aquí, reforzada por quien debería desvirgarla, también en tres planos: mítico (Hemón, hijo de Creonte), artístico (Raniero de Mónaco, que casó con la actriz Grace Kelly, ícono del cine) y político (Carlos de España, puesto en el trono por Franco). Este uso de su otra mitad, de su doble que se entrega al poder, le hubiese dado la posibilidad de parir "nuevos principes" como perpetuación de la estirpe y del poder ${ }^{14}$, y por tanto dejando de lado sus ideales ético-religiosos y optando por el pensamiento político en bien de la ciudad, que se traduce en una verdadera corrupción.

El Prefacio se cierra con un estribillo que resume lo anteriormente expuesto, funcionando como clave de lectura de la obra: "Tenemos una Antígona

${ }^{12}$ Riaza, Antígona... ;Cerda! (1983: 255, v.10).

${ }_{13}$ Sófocles, Antígona, v. 815.

${ }^{14} \mathrm{El}$ tema de la "perpetuación de la especie" como imagen de la perpetuación en el poder se encuentra en otras producciones de Riaza, como por ejemplo Los perros (1986). Para una contextualización de la obra de Riaza en el período de transición, cf. Oliva (2007: 238-239). 
roja / y una Antígona cerda, arrebujadas / ambas dos bajo el mismo pellejo / en forma de bicéfalo revoltijo, / o del doble de novelero prestigio". Para Riaza, los mitos clásicos contienen ya todos los componentes de la modernidad: en la Antígona mítica ya se encuentra la posibilidad del trastocamiento de valores y de la actitud acomodaticia en relación con las instancias de poder que la Antígona contemporánea concentra en su persona.

\section{Antígona, espacio del desmonte}

La desarticulación del mito y su subversión no se dan solamente al nivel del texto, como hemos visto, sino que Riaza despliega una serie de procedimientos escénicos que tienden a hacer visible tal desarticulación. A caballo entre los preceptos simbolistas, presentes ya en la tradición dramática española, como ser el concebir el espacio escénico como todo un símbolo (espacio central, potente iluminación, blancura total de la plataforma), encontramos también elementos de las vanguardias más recientes y del teatro de la crueldad de Artaud (pedazos de carne sanguinolenta, colgajos, animales muertos, maniquíes, piezas ortopédicas $)^{15}$. El espacio se convierte así en símbolo de la violencia que atestigua por un lado la tradición mítica que sustenta la historia de Antígona (el fraticidio de Polinice y Etéocles se constituye en imagen de una inútil guerra intestina, y señala el final de una estirpe) y por otro su correlato con la historia pasada reciente: la Guerra Civil, fraticidio violento que signó a España y se continuó en la dictadura de Franco. El espacio de la sociedad, la pólis, es desmontada, demolida, quebrada y pasa a ser un espacio vacío, espacio de la representación de la violencia.

Los elementos escénicos marcan quiebres en la tradición y demuelen el mito bajo la lógica de la sustitución, uno de los ejes centrales de la poética riaciana. Así, los pollos muertos que encuentra el Coro sustituyen a Etéocles y Polinices, la decoración Luis XV sustituye el espacio del palacio de Tebas por el de El Pardo en Madrid ${ }^{16}$.

Siempre en esta lógica de la sustitución, el personaje de Ismene-CreónHemón también se liga al pasado clásico (el segundo actor representaba más de un personaje en la tragedia, con ayuda de la máscara) y al mismo tiempo muestra una indefinición sexual ligada al cambio de postura política de esos tres personajes, conformando así una tríada viciosa, sin solución y que puede

15 Elementos de la tradición dramática española los encontramos en Valle-Inclán, donde la didascalia escénica conforma un todo que intenta dar hasta el mínimo detalle, conformando el ambiente ideal donde surje el esperpento como deformación de la realidad, y en García Lorca, por ejemplo, en la presentación del espacio en La casa de Bernarda Alba: "Habitación blanquísima del interior de la casa de Bernarda" (Acto I).

${ }^{16}$ Riaza, Antígona... ;Cerda! (1983: 259) 
verse también a nivel del texto, en la ambigüedad del género: "Se destapa IsmeneCreón-Hemón. Aparece vestida con el atuendo de un moderno joven 'contestatario". Antígona despierta a Ismene ("Despierta, Ismene! ¿Cómo puedes dormir?), pero en realidad no sabemos si es Ismene o Hemón o ambos juntos, pues hacia el final de este diálogo la protagonista se dirige en estos términos: "ANTIGONA (a ISMENE-CREON-HEMON).- ;Ya me lo has dicho! Tú prefieres continuar con tu situación. Agarrado como un piojo a tus privilegios de principito regalado "17.

$\mathrm{El}$ encuentro con Creón enfrenta a Antígona con el discurso del poder instalado que "tienta" a la revolucionaria. Este diálogo puede incluso leerse de modo intertextual, puesto que el tío la tienta como si del mismo demonio se tratara al tentar a Jesús: "ISMENE-CREÓN-HEMÓN.- Pues ya ves: también esta vez me acordé. (Se acerca al arca. Saca el collar que llevaba en su faceta isménica. Selo tiende a ANTÍGONA. Ésta lo coge un momento. Lo contempla). ANTÍGONA.La primera de tus tentaciones: la falsa revolución... [...]; Cerdo asqueroso...! Guárdate las estúpidas cáscaras de tu revolución reducida a los signos y a los gestos... ISMENECREON-HEMÓN.- ¿¿Dónde quieres llegar, Antígona? ANTIGONA.- ...Signos que, al propio tiempo, te engordan la faltriquera vendiéndolos como pan caliente a los consumidores de collares, de amuletos, de cantantes rebeldes... ;Rey tendero!; Cerdo, cerdo, cerdo, cerdo...!"18 Es la tentación a la corrupción del poder, al bienestar a costa de la traición. Si no acepta, si no quebranta los ideales del sacrificio, quizás "le arranquen la lengua en algún cuartito de tus sótanos", donde se nota una clara alusión al modus operandi del franquismo: la tortura.

Riaza, en la voz de Antígona, también critica el teatro burgués, que ha transado con el poder: "iMi tío resultó ser todo un orador! Tu Consejo de matusalenes seguro que te aplaudirá a rabiar con piezas semejantes. ¿PPr qué no te dedicas al teatro?" Para nuestro dramaturgo, el teatro burgues señala la muerte del teatro, y el único modo de hacerlo renacer es justamente recurriendo a la ceremonia, al rito como origen del mismo; de ahí los recursos escénicos y poéticos que emplea en sus obras. No solamente el teatro es criticado como institución cultural, sino también la Iglesia como aparato de legitimación del poder:

"ANTÍGONA.- [...] Pero no estoy dispuesta a dar gusto a esos verdugos patriotas. No baréis de mi cuerpo el pan de vuestra cena de compinches. Ni de mi sangre, el vinillo que moje vuestro almuerzo de trabajo. ¡No habrá transubstanciación ni víctima emisaria!"'19 Sobre la base del texto de la consagración del pan y del vino, Antígona reniega del sacrificio, renuncia a los ideales de cambio, termina ahogando la voz de la libertad uniéndose al príncipe heredero, Hemón:

\footnotetext{
${ }^{17}$ Riaza, Antígona... ;Cerda! (1983: 265)

${ }^{18}$ Riaza, Antígona... iCerda! (1983: 269-270)

${ }^{19}$ Riaza, Antígona... ; Cerda! (1983: 273).
} 
“Matrimoniaremos, engendrarás en mí reyes y reyes, yo pariré para tí reyes y reyes, y colorín, colorado...!'20

A partir de este momento, asistimos a la transformación del personaje y al final de la obra. Toda la escena se transforma junto con Antígona: pasa de ser roja a cerda, el pollo-Polinices es descolgado y se transforma en el plato del banquete. Todo ha vuelto a una aparente "normalidad". Ambos han derrocado al "vendido pelele de palacio", pero reproducen ellos mismos el esquema de poder, instalándose en el trono de Tebas. La mención de la peste, en el final, última palabra en boca de la protagonista, denota un doble significado y nos da la clave final de interpretación: la peste del poder transforma, quebranta, corroe y tiene como consecuencia el desencanto, la renuncia. Hemón es ahora el rey Edipo. Antígona es su esposa. Ambos comparten el trono. La peste -mitológica como la de Tebas en los tiempos de Edipo, actual como la heredada del franquismono se ha ido, vuelve a la ciudad, y las instituciones políticas, para Riaza, no han sido sanadas o libradas del flagelo.

${ }^{20}$ Riaza, Antígona... ;Cerda! (1983: 273). 